\title{
Cannabinoid CB1 Receptor Mediates Fear Extinction via Habituation-Like Processes
}

\author{
Kornelia Kamprath, ${ }^{1}$ Giovanni Marsicano, ${ }^{2,4}$ Jianrong Tang, ${ }^{1}$ Krisztina Monory, ${ }^{2,4}$ Tiziana Bisogno, ${ }^{3}$ \\ Vincenzo Di Marzo, ${ }^{3}$ Beat Lutz, ${ }^{2,4}$ and Carsten T. Wotjak ${ }^{1}$ \\ ${ }^{1}$ Neuronal Plasticity/Mouse Behavior Group and 2Molecular Genetics of Behavior Group, Max Planck Institute of Psychiatry, D-80804 Munich, Germany, \\ ${ }^{3}$ Endocannabinoid Research Group, Institute Biomolecular Chemistry, 80078 Pozzuoli/Naples, Italy, and ${ }^{4}$ Department of Physiological Chemistry, Johannes \\ Gutenberg University, 51099 Mainz, Germany
}

The interplay between fear expression and fear extinction provides an important prerequisite for adequate coping with aversive encounters. Current models propose that extinction of conditioned fear is mediated by associative safety learning. Here, we demonstrate that the cannabinoid CB1 receptor, which is crucially involved in fear extinction, is dispensable for associative safety learning. In fact, our results indicate that CB1 mediates fear extinction primarily via habituation-like processes. CB1 null-mutant mice were severely impaired not only in extinction of the fear response to a tone after fear conditioning but also in habituation of the fear response to a tone after sensitization with an inescapable footshock. Surprisingly, long-term habituation was generally affected even in situations with proper short-term adaptation, suggesting the existence of two separated CB1-dependent effector systems for short- and long-term fear adaptation. Our findings underscore the importance of habituation as a determinant of fear extinction in mice and characterize the cannabinoid $\mathrm{CB} 1$ receptor as an essential molecular correlate of this process.

Key words: sensitization; fear conditioning; anxiety; memory; endocannabinoids; stress

\section{Introduction}

In laboratory animals, a discrete stimulus (e.g., a tone) can elicit fear reactions (e.g., freezing) in multiple ways: for example, a tone may trigger an innate fear response in naive animals once its intensity exceeds a certain threshold (Ohman and Mineka, 2001; Lamprea et al., 2002). This threshold critically depends on the life history of the animals, because previous aversive encounters (e.g., a footshock) are able to sensitize animals to tones (Kamprath and Wotjak, 2004). Sensitization is a nonassociative learning process characterized by the general increase in responsiveness to potentially harmful stimuli after an aversive/stressful experience. Accordingly, inescapable footshocks result in long-lasting alterations in behavioral and endocrine parameters (Van Dijken et al., 1992a,b, 1993). On the other hand, if a tone was explicitly paired with a punishment, as done in fear conditioning paradigms, reexposure to the tone activates the memory of the tone-punishment association and thus causes a conditioned freezing response (LeDoux, 2000; Maren and Quirk, 2004). In a typical fearconditioning task, however, associative learning and sensitization (caused by application of an inescapable footshock during fear conditioning) may occur in parallel, with the consequence

Received Jan. 13, 2006; revised April 5, 2006; accepted April 25, 2006

This work was supported by VolkswagenStiftung Grants I/78560 (B.L.), I/78561 (V.D.M.), and I/78 562 (C.T.W.), Deutsche Forschungsgemeinschaft Grant Lu755/1-3 (B.L.), and by a Marie Curie Postdoctoral Fellowship to K.M. (Contract QLGI-CT-2002-51742).

Correspondence should be addressed to Dr. Carsten T. Wotjak at the above address. E-mail: wotjak@mpipsykl.mpg.de.

J. Tang's present address: Department of Neuroscience, Baylor College of Medicine, Houston, TX 77030.

D0I:10.1523/JNEUROSCI.0153-06.2006

Copyright $\odot 2006$ Society for Neuroscience $\quad 0270-6474 / 06 / 266677-10 \$ 15.00 / 0$ that freezing responses of conditioned mice to the tone are determined by both associative and nonassociative memory components (Kamprath and Wotjak, 2004).

In an auditory fear-conditioning task, not only fear acquisition but also fear extinction can be achieved by associative and/or nonassociative learning processes. On the one hand, animals might form an association between the tone and the nonappearance of the predicted punishment (safety learning) that suppresses expression of the memory of the tone-shock association in a process called extinction (for review, see Myers and Davis, 2002). On the other hand, repeated nonreinforced tone presentations may decrease the responsiveness to the tone in the stimulus-response pathways because of habituation-like processes (Thompson and Spencer, 1966; Groves and Thompson, 1970; McSweeney and Swindell, 2002; Kamprath and Wotjak, 2004). In the recent years, molecular correlates of extinction were identified (for review, see Myers and Davis, 2002). Among them, the cannabinoid CB1 receptor (CB1) (for review, see Di Marzo et al., 2004) plays a special role, because its implication in extinction seems to be restricted to aversive test conditions: whereas genetic ablation or pharmacological blockade of CB1 impairs the extinction of fear memories (Marsicano et al., 2002; Suzuki et al., 2004; Chhatwal et al., 2005) and spatial memories acquired under stressful conditions (Varvel and Lichtman, 2002; Varvel et al., 2005), CB1 does not seem to be important for memory extinction in operant conditioning tasks involving positive reinforcement (Holter et al., 2005). One explanation might be that CB1 is not involved in associative extinction learning but rather plays a role in nonassociative learning processes (e.g., habituation), which contribute to the decrease in the fear response (Kamprath and 
Wotjak, 2004). Here, we tested this hypothesis by examining the role of CB1 in extinction and habituation of acquired fear responses. Our results point to an involvement of endocannabinoids in the modulation of habituation-like processes during fear extinction, whereas CB1 seems to be dispensable for associative safety learning.

\section{Materials and Methods}

Animals

All experiments were approved by the Committee on Animal Health and Care of the State of Bavaria (Regierung von Oberbayern) and performed in strict compliance with the European Union recommendations for the care and use of laboratory animals (86/609/CEE).

A total of 118 male cannabinoid CB1 receptor null-mutant mice $\left(\mathrm{CB} 1^{-l-}\right), 135$ male wild-type littermate controls $\left(\mathrm{CB} 1^{+/+}\right)$, and 34 male C57BL/6NCrl mice (Charles River, Sulzfeld, Germany) were included in the experiments. $\mathrm{CB}^{-/-}$and $\mathrm{CB} 1^{+/+}$derived from heterozygous breeding pairs [backcrossed to C57BL/6NCrl to F5/F6 generation (Marsicano et al., 2002)] that were kept in the vivaria of the Forschungszentrum für Umwelt und Gesundheit (Neuherberg, Germany) and the Max Planck Institute of Psychiatry in Munich, Germany. Mice were genotyped after weaning and regenotyped at the end of the experiments as described previously (Marsicano et al., 2002).

All animals were separated at the age of 6-14 weeks and kept singly in standard macrolon type II cages with sawdust bedding (Altromin Faser Einstreu; Altromin, Lage-Lippe, Germany), water and food ad libitum, at $22 \pm 2^{\circ} \mathrm{C}$ room temperature and $55 \pm 5 \%$ humidity, under an inverse $12 \mathrm{~h} \mathrm{light/dark} \mathrm{cycle} \mathrm{(lights} \mathrm{off} \mathrm{at} \mathrm{8:00} \mathrm{A.M.)} \mathrm{for} \mathrm{at} \mathrm{least} 14 \mathrm{~d}$ before starting the experiment.

\section{Experiments}

All experiments were performed during the activity phase (dark phase) of the animals between 9:30 A.M. and 5:00 P.M. Experiments were designed to minimize the number of animals tested. Animals of a given experiment derived from the same batch and were tested simultaneously. Experiments were performed over the course of 3 years.

Conditioning, sensitization, backward conditioning, and unconditioned freezing. Setups and procedures were essentially the same as described previously (Kamprath and Wotjak, 2004). Briefly, two different contexts were used (conditioning chamber and test context) that differed considerably in material, shape, surface texture, bedding, and odor of the cleaning solutions. Mice received the footshocks via metal grid floors in the conditioning chamber (MED Associates, St. Albans, VT). Tones were generated by audio stimulus generators (MED Associates). The animals' behavior was videotaped.

For conditioning, mice were placed in the conditioning context. Three minutes later, a tone $(80 \mathrm{~dB}, 9 \mathrm{kHz}$ sine wave, $10 \mathrm{~ms}$ rising and falling time) was presented to the animals for $20 \mathrm{~s}$ that coterminated with a $2 \mathrm{~s}$ scrambled electric footshock of $0.7 \mathrm{~mA}$. Mice were returned to their home cages 60 s later. For sensitization, mice were treated similarly to the conditioning procedure, except for the fact that only the $2 \mathrm{~s}$ footshock $(0.7 \mathrm{~mA})$ was presented, but not the tone. For backward conditioning, tone and footshock were presented in reverse order compared with the conventional conditioning procedure (i.e., mice perceived a $2 \mathrm{~s}$ footshock of $0.7 \mathrm{~mA} 198 \mathrm{~s}$ after insertion into the conditioning chamber that was immediately followed by a $20 \mathrm{~s}$ tone).

To measure the freezing response to the tone without confounding influences of contextual memory, sensitized and conditioned mice were placed into a neutral environment (test context), and the house light was switched on. Three minutes later, a 3 min tone was presented $(9 \mathrm{kHz} ; 80$ $\mathrm{dB}$ if not stated otherwise). Mice were returned to their home cages $60 \mathrm{~s}$ after the end of tone presentation. For measuring the innate fear response to the tone, naive mice underwent the same test procedure, but with a tone intensity of $95 \mathrm{~dB}$ without previous sensitization/conditioning procedures.

Recording of auditory-evoked potentials. $\mathrm{CB} 1^{-/-}(n=12)$ and $\mathrm{CB}^{+/+}$ $(n=12)$ were chronically equipped with a bipolar recording electrode aimed at the CA1 region of the dorsal hippocampus essentially as described previously (Tang et al., 2003). A recovery period of $14 \mathrm{~d}$ was followed by a test period, in which the optimal tone intensity for auditory-evoked potential recordings was defined for each animal and tone frequency ( 6 or $12 \mathrm{kHz}$ ). Furthermore, the stability of responses was assessed. Animals not showing stable auditory-evoked potentials were excluded from the experiment. Test recordings were followed by the experimental period, which consisted of $2 \mathrm{~d}$ of baseline recording, the conditioning day without recording, and $2 \mathrm{~d}$ of post-conditioning recording (compare Fig. $2 \mathrm{~A}$ for the temporal schedule). At each recording day, mice were slightly anesthetized with isoflurane to connect them to the recording device (Tang et al., 2003) and placed into the test context. After a recovery period of $30 \mathrm{~min}$, auditory-evoked potentials were triggered by series of $9050 \mathrm{~ms}$ tones of either 6 or $12 \mathrm{kHz}$ presented at one tone per second. The two tone series were separated by a $3 \mathrm{~min}$ interval. Tones of $6 \mathrm{kHz}$ always preceded the tones of $12 \mathrm{kHz}$. Three days before conditioning (day -3$)$, intensity-response curves were established for each animal and each tone frequency. Afterward, the intensity of the tones was adjusted individually to cause a $40-50 \%$ maximal excitatory field potential in the subsequent baseline recordings and kept constant throughout the experiment. Basal responses were recorded at days -2 and -1 before conditioning by presenting a single series of 6 and $12 \mathrm{kHz}$ tones. If the basal responses were stable, mice were conditioned the next day (day 0). For each mouse, one of the two tone frequencies was chosen for the conditioned stimulus (CS) in a counterbalanced manner per genotype. The CS+ (paired tone) consisted of a series of $2050 \mathrm{~ms}$ tones of the same characteristics as used for the baseline recordings. The CS+ coterminated with a $1 \mathrm{~s}$ footshock of $0.7 \mathrm{~mA}$. The conditioning procedure was repeated two more times. We have made an effort to minimize the number of tone-shock pairings as well as the intensity of the shock. In our experience (J. Tang and C. T. Wotjak, unpublished observations), the protocol used here is the weakest procedure that consistently caused a potentiation of auditory-evoked potentials in wild-type mice. Most other experiments aimed at measuring learning-induced changes in auditory-evoked potentials used 5-10 tone-shock pairings (Rogan et al., 1997; Tang et al., 2001, 2003). For post-conditioning recordings, mice were transferred back to the electrophysiology laboratory, and the baseline procedure was repeated in the test context.

For data analysis, the 90 auditory-evoked potentials evoked by the 50 $\mathrm{ms}$ tones were averaged per tone series and recording day. Averaged auditory-evoked potentials were analyzed off-line by measuring peak latencies, amplitudes, and slopes of the most negative components as described previously (Tang et al., 2003). Data were normalized to the averaged preconditioning values (baseline, 100\%) separately per animal and tone frequency.

After completion of the experiment, mice were deeply anesthetized with pentobarbital $(100 \mathrm{mg} / \mathrm{kg})$, and an anodal current $(200 \mu \mathrm{A}, 4 \mathrm{~s})$ was passed through the tungsten wire to identify the electrode placement. Approximately 15 min later, animals were killed by an overdose of isoflurane and their brains were removed. Electrode placement was assessed in $20 \mu \mathrm{m}$ cryosections stained with cresyl violet. Animals with a misplaced recording electrode were excluded from analysis.

Drugs. SR141716A [Rimonabant, $3 \mathrm{mg} / \mathrm{kg}$; kindly provided by the National Institute of Mental Health (Bethesda, MD) Chemical Synthesis and Drug Supply Program] was dissolved in vehicle solution $(2.5 \%$ DMSO and 1 drop of Tween 80 per $3 \mathrm{ml}$ of saline) and injected subcutaneously at $20 \mathrm{ml} / \mathrm{kg}$ body weight $30 \mathrm{~min}$ before the behavioral test. Injections were given under light isoflurane anesthesia.

\section{Analyses}

Behavioral analysis. The behavior of the mice was videotaped and scored off-line by trained observers that were blind to the animals' treatment as described previously (Kamprath and Wotjak, 2004). Freezing was defined as the absence of all movements, except for those related to respiration.

Statistical analysis. Data were summarized to distinct intervals, as indicated in the text or the figure legends, and normalized to the respective time. If not stated otherwise, data were analyzed by two-way (genotype/ drug, interval) ANOVA for repeated measures (interval) separately per test day (analysis of the freezing data in $20 \mathrm{~s}$ intervals) or by two-way ANOVA (genotype/drug, day) for repeated measures (day; analysis of the 
A

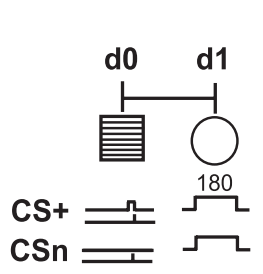

B
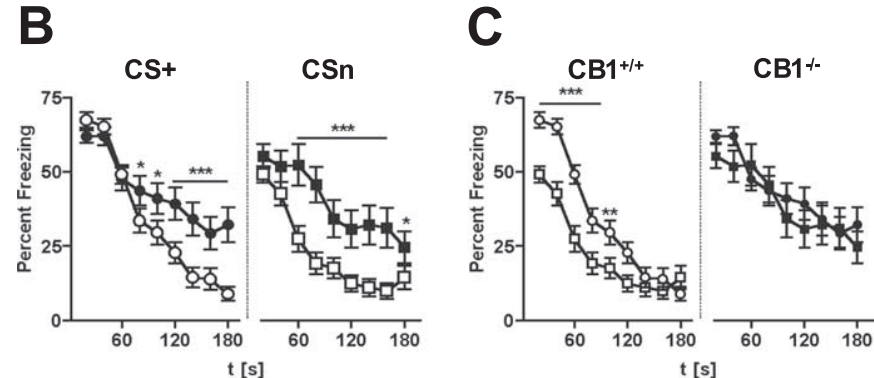

Figure 1. $\quad \mathrm{CB} 1^{-1-}$ mice are impaired in within-session extinction and adaptation, but not in acquisition, of conditioned and sensitized fear. $A, C B 1^{-/-}$and $\mathrm{CB} 1^{+/+}$littermate controls were either conditioned with a single tone-shock pairing or sensitized with a footshock only in the conditioning chamber. All animals were exposed to a $180 \mathrm{~s}$ tone in a neutral environment $24 \mathrm{~h}$ after the conditioning $(\mathrm{CS}+)$ and the sensitization $(\mathrm{CSn})$ procedure, respectively. do, Day 0 ; d1, day 1. B, Both conditioned $\mathrm{CB}^{-1-}(-, n=36)$ and sensitized $\mathrm{CB} 1^{-1-}(\boldsymbol{\square}, n=20)$ showed a sustained freezing response over the course of the 180 s tone presentation compared with the respective $\mathrm{CB}^{+/+}(\mathrm{O}, n=37 ; \square, n=26)$. C, As revealed by comparison of the freezing responses with the tone after conditioning $(\mathrm{CS}+; \mathbf{O}, \bigcirc)$ and sensitization procedures $(\mathrm{CSn} ; \mathbf{\square}, \square)$ separately per genotype, conditioned $\mathrm{CB}^{+/+}$showed a stronger freezing response than sensitized $\mathrm{CB} 1^{+/+}$, whereas conditioned and sensitized $\mathrm{CB} 1^{-/-}$ froze at the same level. Data were normalized to the 20 s observation intervals (mean $\pm \mathrm{SEM}$ ). ${ }^{*} p<0.05,{ }^{* *} p<0.01,{ }^{* * *} p<$ 0.001 versus $\mathrm{CB}^{+/+}(\boldsymbol{B})$ or sensitized $\mathrm{CB} 1^{+/+}(\boldsymbol{C}) . \mathrm{CS}+$, Tone after conditioning procedure; $\mathrm{CSn}$, tone after sensitization procedure.

freezing data averaged over the entire 3 min observation period). Post hoc comparisons were performed by the Newman-Keuls test, if appropriate. Statistical significance was accepted if $p<0.05$. For the sake of clarity and brevity, only relevant results of the statistical analyses are reported. Statistical analyses were performed by specialized software [GraphPad Prism 3.0 (GraphPad, San Diego, CA), Statistica 5.0 (StatSoft, Tulsa, OK), and SPSS version 11.0 (SPSS, Chicago, IL)].

\section{Results}

We refer to procedures with tone-shock pairings as conditioning procedures, with reverse order of shock and tone presentation as backward conditioning ("safety learning") and with shock presentation only as sensitization procedures. The term "sensitization" describes the general increase in responsiveness to potentially harmful stimuli after perception of a punishment, on the basis of nonassociative learning processes. Accordingly, we call mice that underwent sensitization procedures sensitized mice and mice that underwent conditioning procedures conditioned mice. The freezing response of naive (i.e., nonshocked) mice to a tone is called unconditioned freezing or innate fear response. Fear adaptation generally describes the development of the fear response to a tone. More specifically, the decrease in freezing over the course of tone presentation is called within-session extinction after conditioning and within-session adaptation after sensitization procedures. Accordingly, the decrease in freezing from the first to a second tone presentation is called long-term extinction and long-term adaptation/habituation, respectively.

\section{$\mathrm{CB} 1^{-/-}$mice are impaired in within-session extinction and adaptation, but not in acquisition, of conditioned and sensitized fear}

$\mathrm{CB} 1$ plays a crucial role in extinction of the freezing response after fear-conditioning procedures (Marsicano et al., 2002). We wondered whether CB1 is involved in processing of associative or nonassociative memory components that determine extinction of the freezing response of conditioned mice (Kamprath and Wotjak, 2004). Because sensitization of a behavioral response is thought to be a nonassociative learning process that is diminished by counteracting nonassociative adaptation processes (Kamprath and Wotjak, 2004), we compared the tone-induced freezing responses of mice with genetic ablation of $\mathrm{CB} 1 \mathrm{CCB}^{-1-}$ (cf. Marsicano et al., 2002)] with that of their wild-type littermate controls $\left(\mathrm{CB} 1^{+/+}\right)$after conditioning and sensitization procedures.

For conditioning, $\mathrm{CB} 1^{-1-}$ and $\mathrm{CB} 1^{+/+}$received a $0.7 \mathrm{~mA}$ footshock in the conditioning chamber in association with a $20 \mathrm{~s}, 80 \mathrm{~dB}$ tone. On the next day, mice were re-exposed to the same tone in a novel environment (test context) for $3 \mathrm{~min}$ (Fig. $1 A$ ). $\mathrm{CB}^{-/-}$showed a prolonged freezing reaction to the tone compared with $\mathrm{CB} 1^{+/+}$(genotype: $F_{(1,71)}=4.0, p=$ 0.049; genotype-by-interval interaction: $F_{(8,568)}=9.5, p<0.0001$ ) (Fig. $1 B$ ), thus confirming our previous observation of impaired within-session extinction in CB1 ${ }^{-1-}$ (Marsicano et al., 2002; Cannich et al., 2004). It is of note that both genotypes showed similar freezing in the very beginning of the first nonreinforced tone presentation after the conditioning procedure pointing to a normal acquisition of fear conditioning in $\mathrm{CB} 1^{-/-}$(Marsicano et al., 2002).

For sensitization, $\mathrm{CB} 1^{-/-}$and $\mathrm{CB} 1^{+/+}$received a $0.7 \mathrm{~mA}$ footshock in the conditioning chamber without any tone presentation. Mice were subsequently exposed to a $3 \mathrm{~min}$ tone in a novel environment (test context) on the next day, similarly to conditioned mice (Fig. $1 A$ ). Again, $\mathrm{CB} 1^{-1-}$ mice showed a prolonged and stronger freezing reaction to the tone compared with $\mathrm{CB} 1^{+/+}$(genotype: $F_{(1,44)}=9.7, p=0.003$; genotype-by-interval interaction: $\left.F_{(8,352)}=3.5, p<0.001\right)$ (Fig. $1 B$ ). Importantly, both $\mathrm{CB} 1^{-/-}$and $\mathrm{CB} 1^{+/+}$showed the same levels of freezing at the beginning of tone presentation, indicating that $\mathrm{CB} 1$ is not involved in the sensitization process per se. Taking into consideration that the freezing response to a tone after inescapable footshocks is primarily determined by sensitization and nonassociative adaptation processes, the sustained freezing response of $\mathrm{CB} 1^{-1-}$ over the course of tone presentation suggests that $\mathrm{CB} 1$ deficiency delays fear adaptation in a nonassociative manner.

To estimate the contribution of associative memory components to the freezing response of the animals, we compared the freezing response of conditioned and sensitized mice separately per genotype. As expected, conditioned $\mathrm{CB}^{+/+}$showed significantly more freezing to the tone than sensitized $\mathrm{CB} 1^{+/+}$(CS: $F_{(1,61)}=8.8, p=0.004$; CS-by-interval interaction: $F_{(8,488)}=8.2$, $p<0.0001$ ) (Fig. $1 C$ ), indicating that fear conditioning comprises the parallel processing of a stimulus-punishment association and nonassociative sensitization with the consequence that associative and nonassociative memory components together determine the freezing response after conditioning procedures (Kamprath and Wotjak, 2004). In contrast, $\mathrm{CB1}{ }^{-1-}$ showed a similar freezing response to a tone, no matter whether they had received a shock only or whether the tone had been paired with a shock before $\left(\mathrm{CS}: F_{(1,54)}=0.3, p=0.582\right.$; CS-by-interval interaction: $F_{(8,432)}=1.6, p=0.117$ ) (Fig. $1 C$ ). At first sight, these data imply that $\mathrm{CB} 1^{-/-}$were not able to associate tone and footshock during the conditioning procedure, with the consequence that their freezing response was solely determined by nonassociative memory components. However, an intact tone-shock association in $\mathrm{CB} 1^{-1-}$ cannot be entirely ruled out by behavioral data alone, because an impaired adaptation of nonassociative memory com- 
ponents might simply have masked differences in freezing between conditioned and sensitized $\mathrm{CB} 1^{-1-}$. Therefore, we decided to investigate whether $\mathrm{CB} 1^{-/-}$are able to form an associative memory at all by electrophysiological means. To this end, we recorded auditory-evoked potentials in the CA1 region of the dorsal hippocampus of freely behaving $\mathrm{CB}^{-/-}$and $\mathrm{CB} 1^{+/+}$. Evidence exists that conditioning-related changes in auditory-evoked potentials recorded from the lateral amygdala and the CA1 region are exclusively determined by the associative history of the CS (Goosens et al., 2003; Tang et al., 2003). Because both brain structures show a high synchronicity in memory-related changes in neuronal activity (Seidenbecher et al., 2003; Tang et al., 2003), we targeted the more easily accessible CA1 region instead of the lateral amygdala. Moreover, we confirmed that recall of auditory cued fear memories activates the endocannabinoid system not only within the amygdala (Marsicano et al., 2002) but also within the dorsal hippocampus (supplemental Fig. 1, available at www.jneurosci.org as supplemental material).

\section{Potentiation of auditory-evoked potentials after auditory fear conditioning points to normal memory of the tone-shock association in $\mathrm{CB} 1^{-/-}$mice}

Mice were chronically equipped with a recording electrode aimed at the CA1 region of the dorsal hippocampus and tested in a discriminatory fear-conditioning task (Fig. 2A). At first, both 6 and $12 \mathrm{kHz}$ tones were presented to the animals at 2 consecutive days to record a stable baseline. For conditioning, only one of these frequencies was used (i.e., series of either 6 or 12 $\mathrm{kHz}$ tones were paired with a footshock). At the $2 \mathrm{~d}$ after conditioning, series of both 6 and $12 \mathrm{kHz}$ tones were presented to the mice to assess frequency-specific potentiation of auditory-evoked potentials.

Of the 24 animals equipped with electrodes, 11 showed stable responses to the tone series with correct placement of the electrode in the CA1 region of the dorsal hippocampus (Fig. $2 B$ ). During test recordings, $\mathrm{CB} 1^{-/-}(n=5)$ and $\mathrm{CB} 1^{+/+}(n=6)$ showed a similar sensitivity to 6 and $12 \mathrm{kHz}$ tones of increasing intensity (data not shown). Furthermore, there were no genotype differences in basic characteristics of the auditory-evoked potentials assessed at days -2 and -1 before the conditioning procedure (Table 1). Fear conditioning led to a significant potentiation of amplitude [CS: $F_{(1,9)}=13.6, p=0.005$; time: $F_{(3,27)}=6.9, p=$ 0.001 ; CS-by-time interaction: $F_{(3,27)}=5.7, p=0.004$; three-way ANOVA (genotype, CS, time) for repeated measures (CS, time)] (Fig. $2 C)$ and slope $\left(\mathrm{CS}: F_{(1,9)}=11.8, p=0.007\right.$; time: $F_{(3,27)}=$ $14.4, p<0.0001$; CS-by-time interaction: $\left.F_{(3,27)}=8.1, p=0.001\right)$ (Fig. $2 D$ ) of the most-negative-going component of the field EP-
SPs evoked by the paired tones, with no significant differences between $\mathrm{CB} 1^{-/-}$and $\mathrm{CB} 1^{+/+}$in either parameter (genotype: $F_{(1,9)}<0.06, p>0.810$; CS by genotype: $F_{(1,9)}<0.4, p>0.560$; CS by time by genotype: $\left.F_{(1,9) 1,9}<1.3, p>0.300\right)$.

These data show that genetic ablation of $\mathrm{CB} 1$ does not alter the potentiation of auditory-evoked potentials induced by the formation of a tone-shock association, indicating that both $\mathrm{CB} 1^{+/+}$ and $\mathrm{CB1}{ }^{-1-}$ were able to discriminate between paired and neutral tones and therefore to form an associative memory component during fear conditioning. There is still the option that $\mathrm{CB} 1^{-1-}$ might be able to form a tone-shock association after three tone-shock pairings (as used here) but not after a single tone-shock pairing, as used in the behavioral experiments. However, the similar initial freezing response of $\mathrm{CB1}^{-/-}$and $\mathrm{CB} 1^{+/+}$ at day 1 (Fig. $1 B$ ) as well as our previous study showing that 
Table 1. Basic characteristics of auditory-evoked potentials evoked by tone series of two different frequencies within the CA1 region of the dorsal hippocampus in $\mathrm{CB}^{-/-}$ $(n=5)$ and $\mathrm{CB}^{+/+}(n=6)$ during the baseline period day -2 and day -1 (compare Fig. 2$)$

\begin{tabular}{|c|c|c|c|c|c|c|}
\hline \multirow[b]{2}{*}{ Genotype } & \multicolumn{3}{|l|}{$6 \mathrm{kHz}$} & \multicolumn{3}{|l|}{$12 \mathrm{kHz}$} \\
\hline & Latency (ms) & Amplitude ( $\mu \mathrm{V})$ & Slope ( $\mu \mathrm{V} / \mathrm{ms})$ & Latency (ms) & Amplitude ( $\mu \mathrm{V}$ ) & Slope $(\mu \mathrm{V} / \mathrm{ms})$ \\
\hline $\mathrm{CB}^{-1-}$ & $28.9 \pm 2.2$ & $195.6 \pm 44.3$ & $-24.6 \pm 6.0$ & $28.1 \pm 1.8$ & $172.3 \pm 41.3$ & $-21.2 \pm 3.9$ \\
\hline $\mathrm{CB} 1^{+/+}$ & $27.3 \pm 3.1$ & $113.4 \pm 25.0$ & $-21.3 \pm 4.5$ & $27.3 \pm 2.6$ & $144.7 \pm 25.3$ & $-26.3 \pm 5.5$ \\
\hline
\end{tabular}

None of these parameters differed significantly between the two genotypes and the two tone frequencies (genotype: $F_{(1,10)}<1.9, p>0.202 ;$ frequency: $F_{(1,10)}<0.5, p>0.510 ;$ genotype by frequency: $\left.F_{(1,10)}<1.6, p>0.240\right)$.
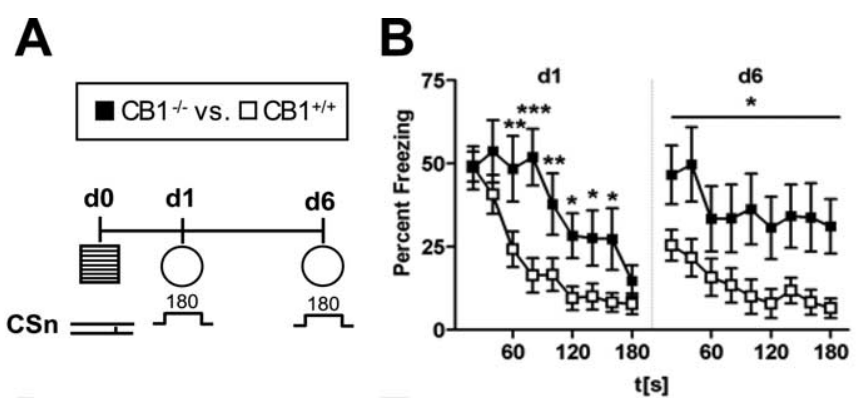

D

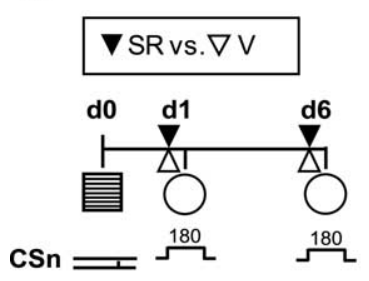

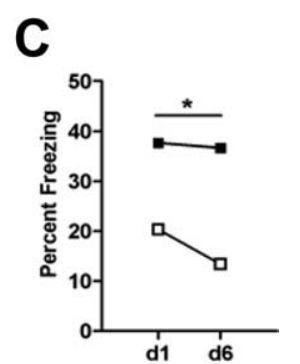

$F$

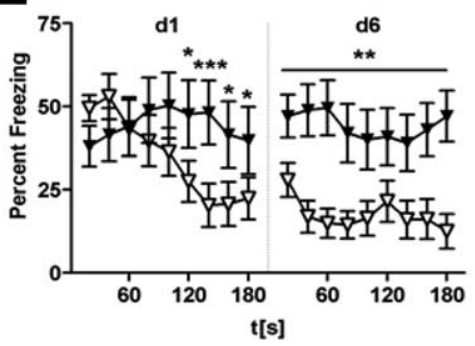

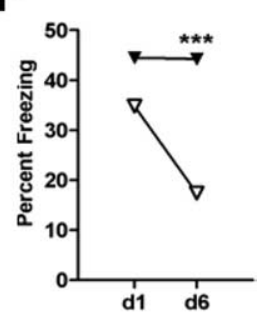

ditionally analyzed freezing responses to the novel context before tone presentation and observed either no or no consistent involvement of CB1 that would support the idea that alterations in context generalization or interference learning could explain the sustained freezing response of $\mathrm{CB} 1^{-/-}$to the tone (supplemental Fig. 3, available at www. jneurosci.org as supplemental material).

\section{CB1 controls both within-session and long-term fear adaptation after sensitization}

In previous studies, we showed that $\mathrm{CB} 1^{-1-}$ are impaired in both withinsession extinction and long-term extinction after fear conditioning (Marsicano et al., 2002; Cannich et al., 2004). Now we investigated the role of CB1 in the decrease in the freezing response after repeated tone presentations after sensitization procedures (Fig. 3A). $\mathrm{CB}^{-1-}$ showed a prolonged and stronger freezing reaction to the tone than $\mathrm{CB} 1^{+/+}$not only during the first tone presentation (genotype: $F_{(1,23)}=$ 7.0, $p=0.014$; genotype by interval: $\left.F_{(8,184)}=2.9, p=0.004\right)$ but also during the second tone presentation $5 \mathrm{~d}$ later (genotype: $\left.F_{(1,22)}=7.8 ; p=0.010\right)$ (Fig. $3 B$ ). The same was the case in wild-type C57BL/6N mice with pharmacological blockade of CB1 with SR141716A before

pharmacological blockade of CB1 before tone re-exposure, but not before conditioning, leads to a sustained freezing response to the tone (Marsicano et al., 2002) strongly argue against impairments in memory acquisition because of CB1 deficiency. Consequently, the similarities in the freezing response of conditioned and sensitized $\mathrm{CB} 1^{-/-}$(Fig. $1 C$ ) cannot be explained by impairments in the formation of associative memories (Varvel and Lichtman, 2002; Cannich et al., 2004; Suzuki et al., 2004; Holter et al., 2005; Varvel et al., 2005), but rather by alterations in the processing of nonassociative memory components after fear conditioning and sensitization procedures.

To further characterize the role of CB1 in fear extinction, from now on we mainly focused on sensitization experiments, because nonassociative memories are directly accessible in such tasks and not confounded by the behavioral expression of associative memory components. Importantly, the nonassociative nature of the sensitization procedures could be confirmed in a control experiment, which demonstrates not only that the increased freezing response to the tone after sensitization persists for $\sim 1$ month but also that it is independent from contextual memory/context generalization (supplemental Fig. 2, available at www.jneurosci.org as supplemental material). To substantiate this conclusion, we ad- tone presentation (Fig. $3 D$ ), both at day 1 (drug by interval: $\left.F_{(8,256)}=5.4, p<0.0001\right)$ and at day 6 (drug: $F_{(1,32)}=9.8 ; p=$ 0.003 ) (Fig. 3E). Accordingly, analysis of the development of the total freezing response from day 1 to day 6 revealed significant effects of genotype $\left(F_{(1,22)}=7.3 ; p=0.012\right)$ (Fig. $3 C$ ) and drug $\left(F_{(1,32)}=4.7 ; p=0.036\right)$ as well a significant drug-by-day interaction $\left(F_{(1,32)}=4.7 ; p=0.037\right)$ (Fig. $\left.3 F\right)$. Whereas $\mathrm{CB} 1^{+/+}$ showed a decrease in freezing from day 1 to day $6\left(t_{(14)}=2.3 ; p=\right.$ 0.039; paired $t$ test), $\mathrm{CB} 1^{-1-}$ failed to do so $\left(t_{(9)}=0.24 ; p=\right.$ $0.815)$ (Fig. 3C). Also, vehicle-treated $\left(t_{(16)}=4.5 ; p<0.0001\right)$ but not antagonist-treated $\left(t_{(16)}=0.03 ; p=0.971\right) \mathrm{C} 57 \mathrm{BL} / 6 \mathrm{~N}$ mice (Fig. $3 F$ ) showed a significant decrease in freezing from day 1 to day 6 . Together, these data demonstrate that the phenotype of $\mathrm{CB} 1^{-1-}$ cannot be ascribed to developmental effects of the mutation or altered fear sensitization but to an acute involvement of CB1 in within-session and in long-term fear adaptation.

\section{$\mathrm{CB} 1^{-/-}$mice show normal safety learning}

In general, the impairment of $\mathrm{CB} 1^{-1-}$ in extinction of the fear response could be explained by an involvement of CB1 either in inhibitory associative (i.e., safety) learning [tone-no shock association (Myers and Davis, 2002)] or in habituation-like processes 
A

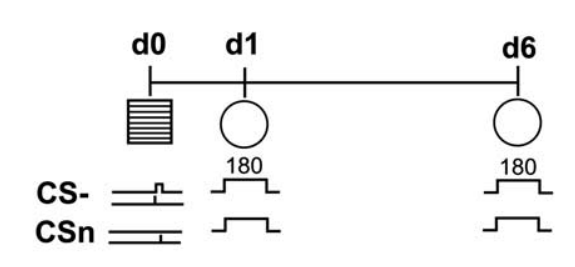

B

C

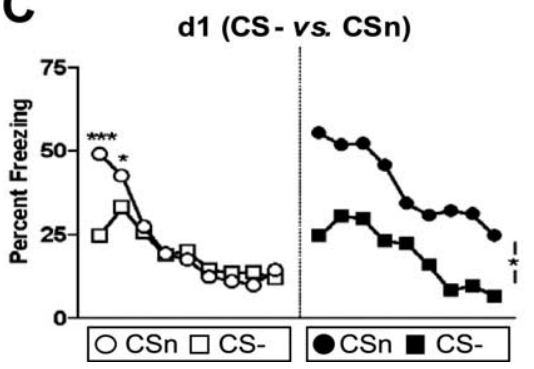

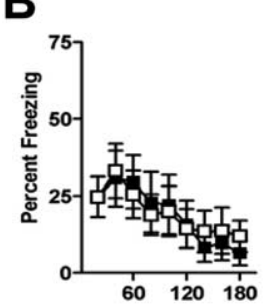

D d1- d6 (Cs-)

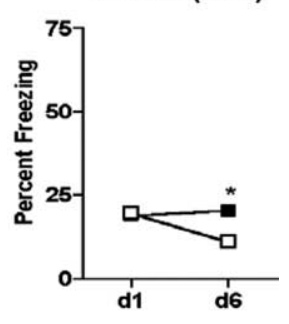

Figure 4. CB1 deficiency does not affect safety learning in a backward conditioning task. $A$, Both $\mathrm{CB}^{-/-}$and $\mathrm{CB}^{+/+}$underwent a backward conditioning procedure in the conditioning chamber, during which application of the footshock preceded the presentation of the 20 s tone. Mice were re-exposed to the tone for $180 \mathrm{~s}$ in the test context the next day and $6 \mathrm{~d}$ later. $\boldsymbol{B}$, $\mathrm{CB}^{-1-}(\square, n=10)$ and $\mathrm{CB} 1^{+/+}(\square, n=12)$ showed the same freezing response to the tone at day 1 after the backward conditioning procedure (mean \pm SEM). C, Both $C B 1^{-1-}$ and $\mathrm{CB}^{+/+}$showed a significantly smaller freezing response to the tone after the backward conditioning procedure compared with the respective sensitized mice $(\mathbf{O}$, ; compare Fig. 1C). $\boldsymbol{D}$, $\mathrm{CB}^{+/+}$, but not $\mathrm{CB} 1^{-/-}$, showed a decrease in the freezing responses to the tones from day 1 to day 6 (mean). Data were normalized either to $20 \mathrm{~s}$ observation intervals $(\boldsymbol{B}, \boldsymbol{C})$ or to the entire 180 s observation period (D). ${ }^{*} p<0.05 ;{ }^{* * *} p<0.001$. $\square$ and $O, \mathrm{CB}^{-1-} ; \square$ and $\bigcirc$, $\mathrm{CB}^{+/+}$. $\mathrm{CS}-$, tone after backward conditioning procedure; $\mathrm{CSn}$, tone after sensitization procedure; $\mathrm{d} 0$, day $0 ; \mathrm{d} 1$, day $1 ; \mathrm{d} 6$, day 6 .

(McSweeney and Swindell, 2002; Kamprath and Wotjak, 2004). The first option seems to be unlikely, because CB1 is dispensable for the formation of associative memories (i.e., tone-shock associations) (Figs. 1,2) and extinction in an appetitive conditioning task (Holter et al., 2005). Nevertheless, because acquisition and extinction of fear behavior could rely on different molecular mechanisms (Suzuki et al., 2004), CB1 could be specifically implicated in extinction of aversive memories through the formation of "tone-no shock" associations. To address this possibility, we tested the tone-no shock association (i.e., safety learning) of $\mathrm{CB} 1^{-1-}$ in a backward conditioning task (Moscovitch and LoLordo, 1968; Mackintosh, 1974), in which the shock preceded the tone presentation (Fig. 4A). After this procedure, there were no significant differences between $\mathrm{CB} 1^{-/-}$and $\mathrm{CB}^{+/+}$in the freezing response to the tone on the next day (Fig. $4 B$ and data not shown). However, both $\mathrm{CB} 1^{+/+}$and $\mathrm{CB} 1^{-1-}$ froze at substantially lower levels than the respective sensitized mice (compare Fig. $1 B$ ), indicating that not only $\mathrm{CB}^{+/+}$(protocol by interval: $\left.F_{(8,288)}=4.5, p<0.0001\right)$ (Fig. $4 C$ ) but also $\mathrm{CB} 1^{-1-}$ (protocol: $F_{(1,28)}=5.6, p=0.025$ ) (Fig. $4 C$ ) were able to form an inhibitory association between the tone and the shock that partially suppressed expression of sensitized fear.

Importantly, although the two genotypes froze at comparable levels at day 1 , they differed in the development of the freezing response from day 1 to day 6 (genotype by day: $F_{(1,20)}=6.4, p=$ $0.020)$ (Fig. $4 D)$ with $\mathrm{CB} 1^{+/+}\left(t_{(11)}=3.1 ; p=0.001\right.$; paired $t$ test) but not $\mathrm{CB} 1^{-1-}\left(t_{(9)}=0.5 ; p=0.606\right)$ decreasing their freezing response on repeated tone presentation. Because safety learning seems to be intact in $\mathrm{CB}^{-1-}$, these differences point to an involvement of CB1 in long-term habituation.

$\mathrm{CB} 1^{-1-}$ mice are impaired in long-term habituation to a tone To test whether CB1 receptors are generally involved in habituation to a tone, we exposed naive (nonshocked) $\mathrm{CB}^{+/+}$and $\mathrm{CB} 1^{-1-}$ mice to a loud $3 \mathrm{~min}$ tone of $95 \mathrm{~dB}$ at days 1 and 6 (Fig. $5 A)$. At day $1, \mathrm{CB}^{-1-}$ and $\mathrm{CB} 1^{+/+}$showed a similar freezing response to this loud tone (genotype: $F_{(1,26)}=0.0, p=0.952$; interval: $F_{(8,208)}=31.0, p<0.0001$; genotype-by-interval interaction: $\left.F_{(8,208)}=0.4, p=0.919\right)$ (Fig. $5 B$ ), indicating that $\mathrm{CB} 1$ does not affect perception of and behavioral response to a loud tone. At day 6, however, $\mathrm{CB} 1^{-1-}$ consistently froze at higher levels than CB1 ${ }^{+/+}$(genotype: $\left.F_{(1,26)}=5.3, p=0.029\right)$ (Fig. $5 B$ ), with no difference in baseline freezing (supplemental Fig. 4, available at www.jneurosci.org as supplemental material). Comparison of the development of the total freezing response from day 1 to day 6 revealed a significant genotype-by-day interaction $\left(F_{(1,26)}=5.8 ; p=0.022\right)$, reflecting the inability of $\mathrm{CB}^{-1-}\left(t_{(12)}\right.$ $=0.3 ; p=0.803$; paired $t$ test $)$ but not $\mathrm{CB} 1^{+/+}\left(t_{(14)}=6.0 ; p<\right.$ $0.0001)$ to decrease their freezing response from day 1 to day 6 (Fig. $5 C$ ). These data indicate that $\mathrm{CB} 1$ plays an important role in long-term habituation to an aversive tone in mice without previous shock experience, even in situations when CB1 is not acutely involved in within-session adaptation during the first tone presentation.

\section{Impairments in the decrease in freezing to a tone in sensitized} $\mathrm{CB} 1^{-1-}$ mice relate to impaired habituation

To confirm that CB1-mediated habituation processes are responsible for the decrease in freezing after repeated tone presentation in sensitized mice, we studied the consequences of pre-exposure to a $3 \mathrm{~min}$ tone of $80 \mathrm{~dB}$ on the freezing response to the same tone presented 1 and $6 \mathrm{~d}$ after sensitization (Fig. $6 \mathrm{~A}$ ). If long-term habituation processes indeed account for adaptation of acquired fear responses, as assessed during a second tone presentation, it should not matter whether the first tone presentation (i.e., the induction of long-term habituation to that stimulus) occurred before or after the sensitization procedure (Kamprath and Wotjak, 2004). Indeed, on day 1 after the sensitization procedure, $\mathrm{CB} 1^{+/+}$with pre-exposure to the tone froze significantly less than $\mathrm{CB1} 1^{+/+}$without tone pre-exposure (protocol: $F_{(1,31)}=$ 11.1, $p=0.002$; protocol by interval: $F_{(8,248)} 2.8, p=0.006$ ) (Fig. $6 B)$. Moreover, $\mathrm{CB} 1^{+/+}$showed similarly low freezing levels during the second tone presentation, regardless of whether the first tone presentation occurred before or after the sensitization procedure (Fig. $6 \mathrm{D}$ ). $\mathrm{CB} 1^{-1-}$, in contrast, showed a strong freezing response at day 1 (protocol: $F_{(1,25)}=0.3, p=0.541$; protocol by interval: $F_{(8,200)}=1.3, p=0.228$ ) (Fig. $6 B$ ), regardless of whether the tone was previously presented or not. Noteworthy, tone preexposure at day 5 (Fig. 6A) elicited only a negligible freezing response compared with mice without tone presentation $\left(\mathrm{CB} 1^{+/+}: 3.0 \pm 0.7 \%\right.$ vs $0.1 \pm 0.0 \%$; $\mathrm{CB}^{-/-}: 3.7 \pm 1.6 \%$ vs $0.5 \pm 0.2 \%$ ) with no differences between the two genotypes (statistics not shown), indicating that expression of fear is not necessary for induction of CB1-dependent long-term habituation to the tone.

At day $6, \mathrm{CB}^{-1-}$ showed a generally increased freezing response compared with CB1 ${ }^{+/+}$(genotype: $F_{(1,56)}=10.6, p=$ 0.002 ) (Fig. $6 C$ ), independently of the protocol [genotype by protocol: $F_{(1,56)}=0.0, p=0.902$; genotype by protocol by interval: $F_{(8,448)}=0.8, p=0.602$; three-way ANOVA (genotype, protocol, interval) for repeated measures (interval)]. As illustrated in Figure $6 \mathrm{E}, \mathrm{CB} 1^{-l-}$ were not at all able to adapt to the tone, despite repeated tone presentations [genotype: $F_{(1,56)}=5.0, p=0.029$; genotype by day: $F_{(1,56)}=15.8, p<0.001$; genotype by protocol 

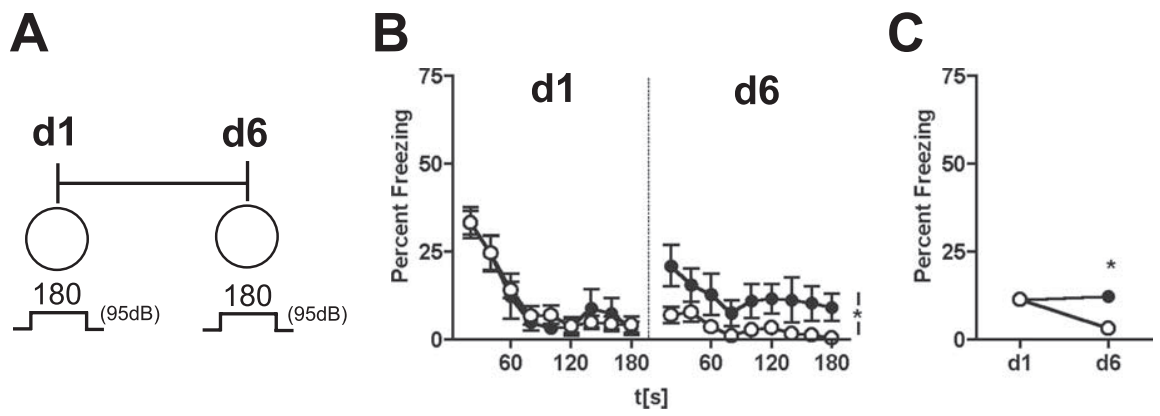

Figure 5. $\quad \mathrm{CB} 1$ deficiency impairs long-term habituation to a loud tone. $A$, Naive $\mathrm{CB}^{-1-}(n=13)$ and $\mathrm{CB} 1^{+/+}(n=15)$ were exposed to a loud tone of $95 \mathrm{~dB}$ at days 1 and $6 . B,\left(B 1^{-1-}\right.$ and $\mathrm{CB} 1^{+/+}$showed a similar short-term habituation to the first tone presentation but differed in their freezing response to the second tone presentation (mean $\pm \mathrm{SEM}$ ). $C, \mathrm{CB}^{+/+}{ }^{+}$, but not $\mathrm{CB}^{-1-}$, showed a decrease in the freezing responses to the tones from day 1 to day 6 (mean). Data were normalized either to $20 \mathrm{~s}$ observation intervals $(\boldsymbol{B})$ or to the entire 180 s observation period $(C){ }^{*} p<0.05 .0, \mathrm{CB}^{-1-} ; \mathrm{O}, \mathrm{CB} 1^{+/+} ; \mathrm{d} 1$, day 1 ; $\mathrm{d} 6$, day 6 .
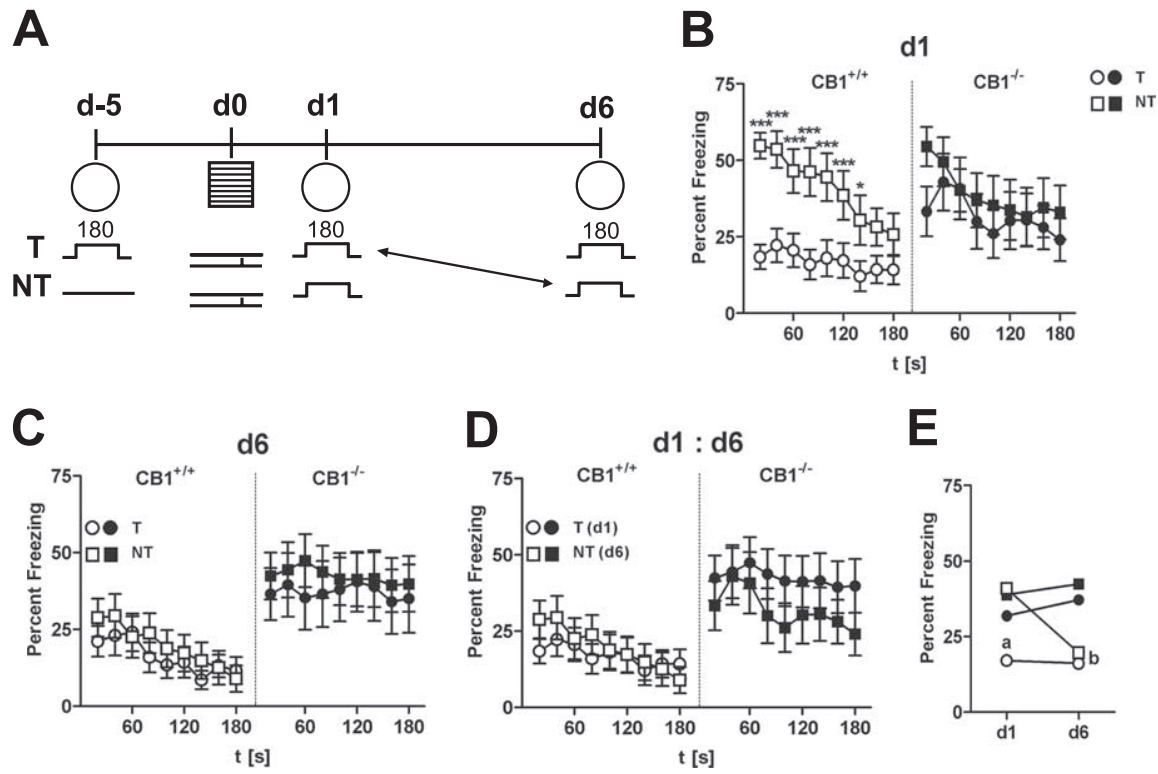

Figure 6. Impaired long-term adaptation in CB1-deficient mice after sensitization results from impaired long-term habituation. $A, C B 1^{-1-}$ and $\mathrm{CB} 1^{+/+}$were randomly assigned to one of two groups. Mice of the first group [tone ( $\left.\mathrm{T}\right) ;\left(\mathrm{C} 1^{-1-}, n=12\right.$; $\left.\mathrm{CB}^{+/+}{ }^{+}, n=17\right]$ were exposed to a 180 s tone in the test context $5 \mathrm{~d}$ before the sensitization procedure. Mice of the second group [no tone (NT); $\left.\mathrm{CB}^{-/-}, n=15 ; \mathrm{CB}^{+/+}, n=16\right]$ were also placed into the test context $5 \mathrm{~d}$ before the sensitization procedure, but without tone presentation. All mice were exposed to $180 \mathrm{~s}$ tones at days 1 and 6 after sensitization with a single $0.7 \mathrm{~mA}$ footshock. $\boldsymbol{B}$, Freezing response to the tone at day 1 . C, Freezing responses to the tone at day $6 . \boldsymbol{D}$, Freezing response to the second tone presentation of mice with (T, day 1 ) and without (NT, day 6 ) tone presentation before the sensitization procedure. $\boldsymbol{E}$, Development of the freezing responses to the tones from days $1-6$. Data were normalized either to $20 \mathrm{~s}$ observation intervals (mean $\pm \mathrm{SEM} ; \boldsymbol{B}-\boldsymbol{D}$ ) or to the entire 180 s observation period (mean; $\boldsymbol{E}$ ). ${ }^{*} p<0.05 ;{ }^{* * *} p<0.001 ;{ }^{\text {a }} p<0.001$ versus all other groups; ${ }^{\mathrm{b}} p<0.0005$ versus the two $\mathrm{CB} 1^{-1-}$ groups. $\mathbf{}, \mathrm{CB} 1^{-1-}$ without tone pre-exposure; $\mathrm{CB} 1^{-1-}$ with tone preexposure; $\square, \mathrm{CB}^{+/+}$without tone pre-exposure; $\mathrm{O}, \mathrm{CB} 1^{+/+}$with tone pre-exposure; $\mathrm{d}-5,5 \mathrm{~d}$ before the sensitization procedure; $\mathrm{d} 0$, day $0 ; \mathrm{d} 1$, day $1 ; \mathrm{d} 6$, day 6 .

by day: $F_{(1,56)}=5.7, p=0.021$; three-way ANOVA (genotype, protocol, day) for repeated measures (day)]. Post hoc analyses revealed that, at day 1 , only $\mathrm{CB} 1^{+/+}$with pre-exposure to the tone froze significantly less than all of the other groups $(p<$ 0.001 ). At day 6, both $\mathrm{CB} 1^{+/+}$groups (with and without preexposure to the tone) froze at similar levels and considerably less than $\mathrm{CB} 1^{-1-}(p<0.001)$. In accordance with our previous observations in naive mice (compare Fig. $5 C$ ), in mice after sensitization (Fig. 3, compare $C, F$ ), and in mice after backward conditioning procedures (compare Fig. $4 D$ ), $\mathrm{CB}^{+/+}$without preexposure to the tone showed a significant decrease in freezing from day 1 to day $6\left(t_{(15)}=32.6 ; p<0.0001\right.$; paired $t$ test $)$,

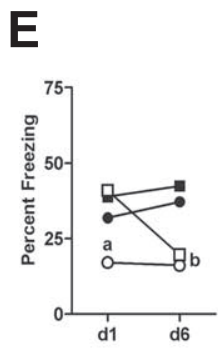

whereas the two $\mathrm{CB} 1^{-1-}$ groups failed to do so $(t<1.2 ; p>0.297)$.

Together, these data demonstrate that in wild-type mice, the decrease in freezing on repeated tone presentation is independent of whether the first tone presentation occurred before or after the sensitization procedure. In CB1-deficient mice, in contrast, pre-exposure to the tone failed to significantly affect the freezing response to a second tone presentation. The most parsimonious interpretation of these observations is that CB1 plays a central role in long-term habituation to the tone and that CB1-dependent habituation primarily accounts for the decrease in acquired fear after sensitization procedures.

\section{Discussion}

Extinction of aversive memories involves at least two different processes: learning about the association between a stimulus and the nonappearance of a punishment [here called safety learning (cf. Myers and Davis, 2002)] and habituation to a repeatedly presented stimulus (cf. McSweeney and Swindell, 2002; Kamprath and Wotjak, 2004). Recent work has shown that different molecular mechanisms relate to different aspects of extinction processing. NMDA receptors, for instance, seem to mediate predominantly associative memory components of extinction (Falls et al., 1992; Santini et al., 2001; Walker et al., 2002). The same is the case for L-type voltage-gated calcium channels (Cain et al., 2002), which are also involved in latent inhibition but not in reduced contingency effects (Cain et al., 2005). Calcineurin, in contrast, mediates extinction by circuit depotentiation (i.e., weakening of the original signaling) (Lin et al., 2003).

Although extinction of conditioned fear critically depends on the endocannabinoid system of the brain (Marsicano et al., 2002; Cannich et al., 2004; Suzuki et al., 2004; Chhatwal et al., 2005), the mechanism by which CB1 mediates fear extinction remained speculative. This study points to a specific involvement of the endocannabinoid system in the habituation component of fear extinction. However, besides habituation, there are still alternative explanations for the data of the present study. For example, the experiment using tone pre-exposure (Fig. 6) strongly resembles latent inhibition procedures, in which pre-exposure to the to-be CS (e.g., a tone) before conditioning results in a decreased conditioned response (e.g., freezing) after conditioning (for review, see Lubow, 1973). When we applied tone pre-exposure before sensitization, we observed a decreased freezing response to the tone after sensitization in $\mathrm{CB} 1^{+/+}$but not in $\mathrm{CB} 1^{-/-}$. Thus, $\mathrm{CB} 1^{-/-}$are possibly impaired in latent inhibition, which belongs, like extinction, to interference paradigms. However, we did not use a true latent inhibition 
paradigm because we used sensitization instead of conditioning: Mice received tone pre-exposure in the test context; $5 \mathrm{~d}$ later they were sensitized in a different context without tone presentation and re-exposed to the tone in the test context. To obtain interference in terms of latent inhibition, the animals should generalize between the different contexts (Bouton, 1993).

Context generalization is known to be a general problem of shock-sensitization paradigms, which relates to the fact that the procedure of shock sensitization is essentially the same as the contextual fear-conditioning procedure. The important difference between these paradigms relates to the test stimuli used for memory retrieval: in contextual fear conditioning, the response to the conditioning context is tested, and in sensitization, the response to an unrelated ("nonassociative") stimulus is tested in a different context. Because shock sensitization of the startle response, which was originally attributed to nonassociative processes (Davis, 1989), was shown to relate to context generalization (Richardson, 2000), the nonassociative nature of fear responses after sensitization is arguable. Thus, freezing responses to the tone after sensitization could be attributed to the fact that the entire experimental procedure, including experimental handling, signals the aversive experience, thus leading to interference learning and context generalization. However, after a contextual fear-conditioning/sensitization procedure, both $\mathrm{CB} 1^{-/-}$and $\mathrm{CB} 1^{+/+}$displayed less conditioned freezing to the "shock context" than to an unconditioned tone in a different context [supplemental Fig. 2 (available at www.jneurosci.org as supplemental material) vs Fig. 3], indicating that the animals used in our experiments are inferior in contextual learning. On repeated nonreinforced exposures to the shock context, $\mathrm{CB} 1^{-/-}$initially developed a more pronounced freezing response, which was later extinguished (supplemental Fig. 2, available at www.jneurosci. org as supplemental material). Nevertheless, $\mathrm{CB1}{ }^{-/-}$still showed considerably more freezing than $\mathrm{CB} 1^{+/+}$to a subsequently presented tone. These results indicate that behavioral adaptation of contextual fear and of unconditioned fear to the tone rely on different mechanisms both involving CB1.

In general, the context is known to play a crucial role in different learning paradigms, for instance in extinction and latent inhibition but also in habituation (Marlin and Miller, 1981; for review, see Bouton, 1993). To further investigate the role of the context in sensitized fear, we additionally analyzed the fear responses to the test context before tone presentation (supplemental Fig. 3, available at www.jneurosci.org as supplemental material). It became evident that $\mathrm{CB}^{-1-}$ froze even less in the test context than $\mathrm{CB} 1^{+/+}$. Moreover, freezing responses to the tone were more pronounced than freezing responses to the test context, thus rendering it unlikely that they result from context generalization. However, application of the CB1 antagonist SR141716A to wild-type mice resulted in slightly increasing fear responses to the context, which was not observed in $\mathrm{CB} 1^{-1-}$ before the first tone exposure (supplemental Fig. 3, available at www.jneurosci.org as supplemental material) and might therefore relate to unspecific effects of SR141716A. Baseline freezing before the second tone exposure was generally increased compared with baseline freezing before the first tone exposure (supplemental Fig. 3, available at www.jneurosci.org as supplemental material). This could be explained by a secondary learning process associating the test context with the aversive tone exposure. Additional experiments are necessary to verify this hypothesis. However, in summary, our data indicate that the role of CB1 in adaptation of sensitized fear to the tone cannot be ascribed to context generalization and thus to differences in extinction of contextual memory. Nevertheless, CB1 seems to be involved, in some aspects, in contextual learning (Suzuki et al., 2004; Pamplona and Takahashi, 2006). The underlying mechanisms remain to be investigated, but they seem to be independent from CB1mediated habituation of the fear response to the tone.

In some of our experiments (e.g., unconditioned freezing to a loud tone, backward conditioning, tone pre-exposure), CB1 was shown to mediate long-term habituation without affecting within-session fear adaptation during the first tone presentation. It is likely that the sensitization procedure acutely activates certain neurotransmitter/modulator systems (e.g., corticotrophinreleasing hormone) (Koob et al., 1993; Walker et al., 2003), which in turn increase the general responsiveness to potentially dangerous stimuli. During the first tone presentation, endocannabinoids may counteract this potentiation as retrograde messengers that reduce neurotransmitter release from presynaptic terminals (Schlicker and Kathmann, 2001; Alger, 2002; Wilson and Nicoll, 2002; Freund et al., 2003) once the averseness of the situation exceeds a certain intensity. This downregulation of neuronal activation might explicitly involve a reduction in glutamatergic transmission (Marsicano et al., 2003;Azad et al., 2003). For longterm habituation, in contrast, processing of the tone might be accompanied by an activation of the endocannabinoid system within an innate stimulus-response pathway (e.g., Mongeau et al., 2003), even if the tones are not sufficient per se for inducing a significant freezing response. In this scenario, activation of CB1 would lead to changes in neuronal excitability in the stimulusresponse pathway [e.g., by changing the activity status of kinases and phosphatases (Cannich et al., 2004) that have been implicated in long-term retention of extinction of conditioned fear ( $\mathrm{Lu}$ et al., 2001; Lin et al., 2003)]. The differences in the involvement of CB1 in short-term adaptation and long-term habituation might also relate to $\mathrm{CB} 1$ activation on different neuronal populations (Marsicano and Lutz, 1999; Marsicano et al., 2003). It is conceivable that physicochemical characteristics of CB1 (e.g., binding affinity to endocannabinoids) or the spatial proximity of $\mathrm{CB} 1$ to the release sites of endocannabinoids differ between GABAergic interneurons and glutamatergic neurons. In addition, CB1 might be coupled to different intracellular pathways, in particular, because GABAergic interneurons do not express the phosphatase calcineurin (Sik et al., 1998).

In general, the involvement of CB1 in fear extinction strikingly resembles the role of the endocannabinoid system in adaptation of stress responses (for review, see Hill and Gorzalka, 2005; Viveros et al., 2005). This has potential implications for the interaction of the two processes (for review, see Korte, 2001), in particular because tone presentations after fear conditioning or sensitization procedures can be regarded as psychological stressors. Nevertheless, it seems to be unlikely that a sustained activation of the hypothalamic-pituitary-adrenocortical axis in CB1deficient mice after stressor exposure (Cota et al., 2003; Di et al., 2003) plays a significant role in within-session extinction of the fear response, because unrestrained release of corticosterone attributable to CB1 deficiency would be expected to facilitate rather than to attenuate fear extinction (Yang et al., 2006). Long-term fear extinction, in contrast, might well share common mechanisms with adaptation to homotypic stressors. In this context, Patel et al. (2005) showed that the endocannabinoid system mediates habituation to repeated restraint stress. They observed an increase in the level of 2-arachidonoyl glycerol in brain punches from the amygdala complex from the first to the fifth restraint stress episode. Furthermore, pharmacological blockade of CB1 during the fifth restraint episode resulted in a reversal of the 
habituation-like reduction in Fos expression in the infralimbic and prelimbic cortices (Patel et al., 2005). Interestingly, these brain regions are known to play a pivotal role in extinction of conditioned fear (Milad and Quirk, 2002; Quirk et al., 2003; Pare et al., 2004) and therefore may be involved in the endocannabinoid-mediated long-term habituation described in the present study as well.

In summary, our study provides a new conceptual framework for understanding the role of CB1 in short- and long-term adaptation to aversive situations and emphasizes the importance of CB1-mediated habituation in extinction of acquired fear. Our protocol of prolonged stimulus presentations resembles the principle of exposure therapy, which is successfully used for the treatment of phobias and posttraumatic stress disorder (Wolpe, 1958; Bartling et al., 1980; Ost et al., 1991; Foa and Riggs, 1993). Our findings imply that the success of such therapies is, at least partially, based on successful habituation, thus suggesting the endocannabinoid system as both a vulnerability factor and potential therapeutic target of anxiety disorders.

\section{References}

Alger BE (2002) Retrograde signaling in the regulation of synaptic transmission: focus on endocannabinoids. Prog Neurobiol 68:247-286.

Azad SC, Eder M, Marsicano G, Lutz B, Zieglgansberger W, Rammes G (2003) Activation of the cannabinoid receptor type 1 decreases glutamatergic and GABAergic synaptic transmission in the lateral amygdala of the mouse. Learn Mem 10:116-128.

Bartling G, Fiegenbaum W, Krause R (1980) Reizüberflutung. Theorie und Praxis. Stuttgart, Germany: Kohlhammer.

Bouton ME (1993) Context, time, and memory retrieval in the interference paradigms of Pavlovian learning. Psychol Bull 114:80-99.

Cain CK, Blouin AM, Barad M (2002) L-type voltage-gated calcium channels are required for extinction, but not for acquisition or expression, of conditional fear in mice. J Neurosci 22:9113-9121.

Cain CK, Godsil BP, Jami S, Barad M (2005) The L-type calcium channel blocker nifedipine impairs extinction, but not reduced contingency effects, in mice. Learn Mem 12:277-284.

Cannich A, Wotjak CT, Kamprath K, Hermann H, Lutz B, Marsicano G (2004) CB1 cannabinoid receptors modulate kinase and phosphatase activity during extinction of conditioned fear in mice. Learn Mem 11:625-632.

Chhatwal JP, Davis M, Maguschak KA, Ressler KJ (2005) Enhancing cannabinoid neurotransmission augments the extinction of conditioned fear. Neuropsychopharmacology 30:516-524.

Cota D, Marsicano G, Tschop M, Grubler Y, Flachskamm C, Schubert M, Auer D, Yassouridis A, Thone-Reineke C, Ortmann S, Tomassoni F, Cervino C, Nisoli E, Linthorst AC, Pasquali R, Lutz B, Stalla GK, Pagotto U (2003) The endogenous cannabinoid system affects energy balance via central orexigenic drive and peripheral lipogenesis. J Clin Invest 112:423-431.

Davis M (1989) Sensitization of the acoustic startle reflex by footshock. Behav Neurosci 103:495-503.

Di S, Malcher-Lopes R, Halmos KC, Tasker JG (2003) Nongenomic glucocorticoid inhibition via endocannabinoid release in the hypothalamus: a fast feedback mechanism. J Neurosci 23:4850-4857.

Di Marzo V, Bifulco M, De Petrocellis L (2004) The endocannabinoid system and its therapeutic exploitation. Nat Rev Drug Discov 3:771-784.

Falls WA, Miserendino MJ, Davis M (1992) Extinction of fear-potentiated startle: blockade by infusion of an NMDA antagonist into the amygdala. J Neurosci 12:854-863.

Foa EB, Riggs DS (1993) Post-traumatic stress disorder in rape victims. In: American Psychiatric Press review of psychiatry (Oldham J, Riba MB, Tasman A, eds), pp 273-303. Washington, DC: American Psychiatric.

Franklin KN, Paxinos G (1997) The mouse brain in stereotactic coordinates. London: Academic.

Freund TF, Katona I, Piomelli D (2003) Role of endogenous cannabinoids in synaptic signaling. Physiol Rev 83:1017-1066.

Goosens KA, Hobin JA, Maren S (2003) Auditory-evoked spike firing in the lateral amygdala and Pavlovian fear conditioning: mnemonic code or fear bias? Neuron 40:1013-1022.
Groves PM, Thompson RF (1970) Habituation: a dual-process theory. Psychol Rev 77:419-450.

Hill MN, Gorzalka BB (2005) Is there a role for the endocannabinoid system in the etiology and treatment of melancholic depression? Behav Pharmacol 16:333-352.

Holter SM, Kallnik M, Wurst W, Marsicano G, Lutz B, Wotjak CT (2005) Cannabinoid CB1 receptor is dispensable for memory extinction in an appetitively-motivated learning task. Eur J Pharmacol 510:69-74.

Kamprath K, Wotjak CT (2004) Nonassociative learning processes determine expression and extinction of conditioned fear in mice. Learn Mem 11:770-786.

Koob GF, Heinrichs SC, Pich EM, Menzaghi F, Baldwin H, Miczek K, Britton KT (1993) The role of corticotropin-releasing factor in behavioural responses to stress. Ciba Found Symp 172:277-289.

Korte SM (2001) Corticosteroids in relation to fear, anxiety and psychopathology. Neurosci Biobehav Rev 25:117-142.

Lamprea MR, Cardenas FP, Vianna DM, Castilho VM, Cruz-Morales SE, Brandao ML (2002) The distribution of fos immunoreactivity in rat brain following freezing and escape responses elicited by electrical stimulation of the inferior colliculus. Brain Res 950:186-194.

LeDoux JE (2000) Emotion circuits in the brain. Annu Rev Neurosci 23:155-184.

Lin CH, Yeh SH, Leu TH, Chang WC, Wang ST, Gean PW (2003) Identification of calcineurin as a key signal in the extinction of fear memory. J Neurosci 23:1574-1579.

Lu KT, Walker DL, Davis M (2001) Mitogen-activated protein kinase cascade in the basolateral nucleus of amygdala is involved in extinction of fear-potentiated startle. J Neurosci 21:RC162(1-5).

Lubow RE (1973) Latent inhibition. Psychol Bull 79:398-407.

Mackintosh NJ (1974) The psychology of animal learning. London: Academic.

Maren S, Quirk GJ (2004) Neuronal signalling of fear memory. Nat Rev Neurosci 5:844-852.

Marlin NA, Miller RR (1981) Associations to contextual stimuli as a determinant of long-term habituation. J Exp Psychol Anim Behav Process 7:313-333

Marsicano G, Lutz B (1999) Expression of the cannabinoid receptor CB1 in distinct neuronal subpopulations in the adult mouse forebrain. Eur J Neurosci 11:4213-4225.

Marsicano G, Wotjak CT, Azad SC, Bisogno T, Rammes G, Cascio MG, Hermann H, Tang J, Hofmann C, Zieglgansberger W, Di M, V, Lutz B (2002) The endogenous cannabinoid system controls extinction of aversive memories. Nature 418:530-534.

Marsicano G, Goodenough S, Monory K, Hermann H, Eder M, Cannich A, Azad SC, Cascio MG, Gutierrez SO, van der SM, Lopez-Rodriguez ML, Casanova E, Schutz G, Zieglgansberger W, Di M, V, Behl C, Lutz B (2003) $\mathrm{CB} 1$ cannabinoid receptors and on-demand defense against excitotoxicity. Science 302:84-88.

McSweeney FK, Swindell S (2002) Common processes may contribute to extinction and habituation. J Gen Psychol 129:364-400.

Milad MR, Quirk GJ (2002) Neurons in medial prefrontal cortex signal memory for fear extinction. Nature 420:70-74.

Mongeau R, Miller GA, Chiang E, Anderson DJ (2003) Neural correlates of competing fear behaviors evoked by an innately aversive stimulus. J Neurosci 23:3855-3868.

Moscovitch A, LoLordo VM (1968) Role of safety in the Pavlovian backward fear conditioning procedure. J Comp Physiol Psychol 66:673-678.

Myers KM, Davis M (2002) Behavioral and neural analysis of extinction. Neuron 36:567-584.

Ohman A, Mineka S (2001) Fears, phobias, and preparedness: toward an evolved module of fear and fear learning. Psychol Rev 108:483-522.

Ost LG, Salkovskis PM, Hellstrom K (1991) One-session therapist-directed exposure vs self-exposure in the treatment of spider phobia. Behav Ther 22:407-422.

Pamplona FA, Takahashi RN (2006) WIN 55212-2 impairs contextual fear conditioning through the activation of CB1 cannabinoid receptors. Neurosci Lett 397:88-92.

Pare D, Quirk GJ, LeDoux JE (2004) New vistas on amygdala networks in conditioned fear. J Neurophysiol 92:1-9.

Patel S, Roelke CT, Rademacher DJ, Hillard CJ (2005) Inhibition of restraint stress-induced neural and behavioural activation by endogenous cannabinoid signalling. Eur J Neurosci 21:1057-1069. 
Quirk GJ, Likhtik E, Pelletier JG, Pare D (2003) Stimulation of medial prefrontal cortex decreases the responsiveness of central amygdala output neurons. J Neurosci 23:8800-8807.

Richardson R (2000) Shock sensitization of startle: learned or unlearned fear? Behav Brain Res 110:109-117.

Rogan MT, Staubli UV, LeDoux JE (1997) Fear conditioning induces associative long-term potentiation in the amygdala. Nature 390:604-607.

Santini E, Muller RU, Quirk GJ (2001) Consolidation of extinction learning involves transfer from NMDA-independent to NMDA-dependent memory. J Neurosci 21:9009-9017.

Schlicker E, Kathmann M (2001) Modulation of transmitter release via presynaptic cannabinoid receptors. Trends Pharmacol Sci 22:565-572.

Seidenbecher T, Laxmi TR, Stork O, Pape HC (2003) Amygdalar and hippocampal theta rhythm synchronization during fear memory retrieval. Science 301:846-850

Sik A, Hajos N, Gulacsi A, Mody I, Freund TF (1998) The absence of a major $\mathrm{Ca}^{2+}$ signaling pathway in GABAergic neurons of the hippocampus. Proc Natl Acad Sci USA 95:3245-3250.

Suzuki A, Josselyn SA, Frankland PW, Masushige S, Silva AJ, Kida S (2004) Memory reconsolidation and extinction have distinct temporal and biochemical signatures. J Neurosci 24:4787-4795.

Tang J, Wotjak CT, Wagner S, Williams G, Schachner M, Dityatev A (2001) Potentiated amygdaloid auditory-evoked potentials and freezing behavior after fear conditioning in mice. Brain Res 919:232-241.

Tang J, Wagner S, Schachner M, Dityatev A, Wotjak CT (2003) Potentiation of amygdaloid and hippocampal auditory-evoked potentials in a discriminatory fear-conditioning task in mice as a function of tone pattern and context. Eur J Neurosci 18:639-650.

Thompson RF, Spencer WA (1966) Habituation: a model phenomenon for the study of neuronal substrates of behavior. Psychol Rev 73:16-43.

Van Dijken HH, Van der Heyden JA, Mos J, Tilders FJ (1992a) Inescapable footshocks induce progressive and long-lasting behavioural changes in male rats. Physiol Behav 51:787-794.

Van Dijken HH, Mos J, Van der Heyden JA, Tilders FJ (1992b) Characterization of stress-induced long-term behavioural changes in rats: evidence in favor of anxiety. Physiol Behav 52:945-951.

Van Dijken HH, de Goeij DC, Sutanto W, Mos J, de Kloet ER, Tilders F (1993) Short inescapable stress produces long-lasting changes in the brain-pituitary-adrenal axis of adult male rats. Neuroendocrinology 58:57-64

Varvel SA, Lichtman AH (2002) Evaluation of CB1 receptor knockout mice in the Morris water maze. J Pharmacol Exp Ther 301:915-924.

Varvel SA, Anum EA, Lichtman AH (2005) Disruption of CB(1) receptor signaling impairs extinction of spatial memory in mice. Psychopharmacology (Berl) 179:863-872.

Viveros MP, Marco EM, File SE (2005) Endocannabinoid system and stress and anxiety responses. Pharmacol Biochem Behav 81:331-342.

Walker DL, Ressler KJ, Lu KT, Davis M (2002) Facilitation of conditioned fear extinction by systemic administration or intra-amygdala infusions of D-cycloserine as assessed with fear-potentiated startle in rats. J Neurosci 22:2343-2351.

Walker DL, Toufexis DJ, Davis M (2003) Role of the bed nucleus of the stria terminalis versus the amygdala in fear, stress, and anxiety. Eur J Pharmacol 463:199-216.

Wilson RI, Nicoll RA (2002) Endocannabinoid signaling in the brain. Science 296:678-682.

Wolpe J (1958) Psychotherapy by reciprocal inhibition. Stanford, CA: Stanford UP.

Yang YL, Chao PK, Lu KT (2006) Systemic and intra-amygdala administration of glucocorticoid agonist and antagonist modulate extinction of conditioned fear. Neuropsychopharmacology 31:912-924. 